\title{
Editorial
}

\section{Detecting COVID-19 infection hotspots using Arogya Setu mobile App}

\author{
Sheikh Mohd Saleem ${ }^{1, *}$ \\ ${ }^{1}$ Health Consultant, Jammu and Kashmir, India
}

\section{A R T I C L E I N F O}

\section{Article history:}

Received 30-12-2020

Accepted 30-12-2020

Available online 08-01-2021
(C) This is an open access article distributed under the terms of the Creative Commons Attribution License (https://creativecommons.org/licenses/by/4.0/) which permits unrestricted use, distribution, and reproduction in any medium, provided the original author and source are credited.
The COVID-19 pandemic is one among the serious concerns World has faced till date. In order to restrict and curb the spread of COVID-19 infection among the population, many countries-imposed restrictions on the mobility of their citizens worldwide, commonly termed as lockdowns. ${ }^{1}$ Some countries eased out lockdowns in a phased manner, while many countries sought reimpositions of lockdowns either nationally or regionally. Such measures were taken to minimize the effect of country wide lockdowns on national economy.

Despite all this, the COVID-19 crisis has also seen a gradual evolution of digitalization through the proliferation of apps and measures undertaken by governments and companies. Some of these measures, such as the introduction and deployment of Arogya Setu, have received a lot of attention beside other non-pharmaceutical measures like "test and treat". The Ministry of Electronics and Information Technology rolled out "Aarogya Setu" application ("the mobile based App") for Android and iOS platforms. The app aims at providing users' information whether they are prone to a COVID-19 infection by analyzing their proximity to COVID-19 positive persons. The app requires the user to submit the user's geo-data. It also uses inbuilt Bluetooth of the mobile device to connect to other registered users and, from the network thus formed, analyze whether the user has come in contact with anyone who has been tested positive. The app, as per its terms of

\footnotetext{
* Corresponding author.

E-mail address: saleem.900@gmail.com (S. M. Saleem).
}

service, is intended to "notify, trace, and suitably support" a registered user regarding COVID-19 infection. ${ }^{2}$ This app "Aarogya Setu" can be a perfect surveillance tool, and can be used to specifically to complement the surveillance activities at the regional level. To contain the virus and avoid its mass spread, the effectiveness of regional activities depends on early identification of hot spots of COVID-19 infection. Interpreting the changes in the infection rate over the time for a specific area or region needs confirmation by mass testing. The testing of the population for the COVID-19 infection using standard detection methods like RT-PCR. Or rapid antigen testing (RAT) can be a costly affair and will require substantial testing capacity at the ground level. ${ }^{3}$ Thus, inadequate testing by the public health organizations to detect rapid changes in the infection rate and COVID-19 spread can significantly delay and hamper public health decisions. There is a high unmet need for tools like Arogya Setu that can facilitate the timely and costeffective identification of hotspots of COVID-19 infection to enable the decision makers to act with minimal delay. ${ }^{3}$ Using such a technology to detect the hotspots of infection will help them decide for lockdown re-impositions at the sub-regional or regional levels. This Arogya Setu app can be a game changer and can help prevent nationwide lockdowns and save national economies from further downfall.

\section{Source of Funding}

Nil. 


\section{Conflict of Interest}

None.

\section{References}

1. WHO. Coronavirus disease (COVID-19): Herd immunity, lockdowns and COVID-19. 2020 [cited 2020 Dec 31]. Available from: https://www.who.int/news-room/q-a-detail/herd-immunitylockdowns-and-covid- 19.

2. Bhandari V. Aarogya Setu and patient tracking tools: A serious infringement of digital privacy | The Indian Express. Indian Express [Internet]. 2020 [cited 2020 Dec 31]. Available from: https://indianexpress.com/article/opinion/aarogya-setu-patienttracking-tool-data-privacy6431644/.
3. Varsavsky T, Graham MS, Canas LS, Ganesh S, Pujol JC, Sudre $\mathrm{CH}$, et al. Detecting COVID-19 infection hotspots in England using large-scale self-reported data from a mobile application: a prospective, observational study. Lancet Public Heal. 2020:100:1010/S2468$2667(20) 30269-3$.

\section{Author biography}

Sheikh Mohd Saleem, Consultant

Cite this article: Saleem SM. Detecting COVID-19 infection hotspots using Arogya Setu mobile App. Indian J Forensic Community Med 2020;7(4):158-159. 